\title{
Antioxidant Therapy in Patients with Severe Aluminum Phosphide Poisoning: A Pilot Study
}

\author{
Ashish Bhalla, P. Jyothinath, Surjit Singh \\ Department of Internal Medicine, Post Graduate Institute of Medical Education and Research, Chandigarh, India
}

\section{Abstract}

Background: N-acetyl cysteine (NAC) is a powerful antioxidant and has been used extensively in the treatment of paracetamol overdose with great success. Aluminum phosphide (ALP) ingestion results in significant oxidative stress. In this study, we evaluated the effects of NAC on mortality in patients with severe ALP poisoning. Subjects and Methods: This prospective intervention study was carried out in the emergency medical unit attached to the Nehru Hospital at PGIMER, Chandigarh, over a period of 1 year. All the patients presenting with severe ALP poisoning were randomized into two group. The treatment group received NAC in the dose of $150 \mathrm{mg} / \mathrm{kg}$ intravenous over $1 \mathrm{~h}$, followed by $50 \mathrm{mg} / \mathrm{kg}$ over $4 \mathrm{~h}$, followed by $100 \mathrm{mg} / \mathrm{kg} 16 \mathrm{~h}$ in $5 \%$ dextrose. The placebo group received $5 \%$ dextrose. The primary end point was mortality. Results: A total of 50 patients were recruited. The baseline parameters were comparable in both groups. The survivors in the treatment group received $19 \mathrm{~g}$ of NAC, but the nonsurvivors received only $12.15 \mathrm{~g}$ of NAC. The overall mortality in the study group was $88 \%$ with $87.5 \%$ mortality in the treatment group and $88.5 \%$ in the placebo group. Conclusions: Antioxidant therapy in the form of NAC in severe ALP poisoning did not confer any survival benefit.

Keywords: Aluminum phosphide, $\mathrm{N}$-acetyl cysteine, oxidative stress, poisoning

\section{INTRODUCTION}

Pesticide poisoning is an important cause of morbidity and mortality in India. ${ }^{[1,2]}$ Aluminum phosphide (ALP) is commonly reported from Northern India but is uncommon in other parts of India as well as in rest of the world. Recently, a few cases have been reported from Iran, Jordan, and Morocco. ${ }^{[3-5]}$

Toxicity of ALP is due to phosphine gas (PH 3). ALP on exposure to moisture or hydrochloric acid releases phosphine (PH 3), which is a mitochondrial poison. At the cellular level, inhibition of cytochrome oxidase leads to disruption of cellular respiration resulting in oxidative stress..$^{[2,6-8]}$ Till date, there is no specific antidote for severe ALP poisoning and treatment is mainly symptomatic. The logical treatment of this cellular dysfunction could be an agent to prevent/protect the cells from the oxidative stress, halting the manifestation due to progressive cellular damage. Various antioxidants such as melatonin have been tried in animal models to counter the effects of $\mathrm{PH} \mathrm{3.}{ }^{[6]}$ In a recent study from Iran, use of N-acetyl cysteine (NAC) has been reported to confer survival benefit along with a reduction in oxidative stress. ${ }^{[7]}$

\begin{tabular}{|l|l|}
\hline \multicolumn{2}{|c|}{ Access this article online } \\
\hline Quick Response Code: & Website: \\
\hline & www.ijccm.org \\
\hline & \\
\hline
\end{tabular}

In this study, we observed the effects of NAC, acetylated form of cysteine, on mortality and morbidity in patients with severe ALP poisoning.

\section{Aim}

This was aimed at exploring the effects of NAC on mortality in patients with severe ALP poisoning.

\section{Subjects and Methods}

This was a prospective intervention study carried out in the emergency medical unit attached to the Nehru Hospital at PGIMER, Chandigarh, over a period of 1 year. All the patients presenting to emergency outpatient department with alleged history of ingestion of ALP was screened and those with shock were eligible for enrollment in the study. Severe

Address for correspondence: Dr. Ashish Bhalla, Department of Internal Medicine, Post Graduate Institute of Medical Education and Research, Chandigarh - 160 012, India. E-mail: bhalla.chd@gmail.com

This is an open access article distributed under the terms of the Creative Commons Attribution-NonCommercial-ShareAlike 3.0 License, which allows others to remix, tweak, and build upon the work non-commercially, as long as the author is credited and the new creations are licensed under the identical terms.

For reprints contact: reprints@medknow.com

How to cite this article: Bhalla A, Jyothinath P, Singh S. Antioxidant therapy in patients with severe aluminum phosphide poisoning: A pilot study. Indian J Crit Care Med 2017;21:836-40. 
ALP poisoning was defined hemodynamic compromise in the form of shock (systolic blood pressure $[\mathrm{SBP}]<90$ ) at the time of presentation in a patient alleged to have exposure to ALP. Written informed consent was obtained from the next to the kin of the patient, before randomization.

Patients with doubtful ingestion of ALP consumption, zinc phosphide consumption, those without shock were excluded. Patients having ingestion of ALP along with other drugs or alcohol and patients with past history of allergy of NAC were along excluded.

On an average, our emergency receives around 1000 cases of poisoning every year and around 150-200 cases of ALP poisoning are reported annually. Out of these, $50 \%$ report with shock and $80 \%$ of the severely poisoned patients die. With a predicted mortality reduction of $50 \%$ the sample size calculated with $95 \%$ confidence interval (CI) was 50 in each arm; however, only 50 patients could be recruited during the study period, making the study underpowered.

Fifty recruited patients were randomized using computer-generated random numbers into two groups, as the treatment group and placebo group. The treating physician was aware of the treatment group, but the patients and the physician analyzing the results were blinded. The demographic variables and vitals were recorded. Both the groups received the same level of supportive care with gastric decontamination using normal saline being performed in both. NAC was administered to one group after dissolving the dose in $5 \%$ dextrose and the other group received only 5\% dextrose (placebo). The patients were followed duly for the development of complications/improvement in the clinical state by monitoring vitals, electrocardiogram (ECG), arterial blood gas, liver function test, renal function test, and signs of capillary leak syndrome. The vitals and ECG were repeated every $2 \mathrm{~h}$ till the time of death or recover.

The primary endpoint in the study group was mortality. Secondary outcomes measures studied were duration of stay, secondary complications such as hepatic failure, multi-organ dysfunction syndrome, and capillary leak syndrome.

The dose of NAC used was same as recommended for use in paracetamol poisoning. A total of $150 \mathrm{mg} / \mathrm{kg}$ was administered intravenously over $1 \mathrm{~h}$ after dilution in $200 \mathrm{ml}$ of $5 \%$ dextrose, followed by $50 \mathrm{mg} / \mathrm{kg}$ in $500 \mathrm{ml}$ of $5 \%$ dextrose over $4 \mathrm{~h}$, followed by $100 \mathrm{mg} / \mathrm{kg}$ in $500 \mathrm{ml}$ over $16 \mathrm{~h}$.

A contiguous variable such as BP, pulse rate, and heart rate (HR) was analyzed by Student's $t$-test results expressed as mean or median. For categorical data such as mortality, proportions within the groups, and the relative risk of death in the NAC as compared with the placebo group was calculated with $95 \%$ CIs, with Chi-square test or Fisher exact test. Kaplan-Meier curve was plotted to compare the mortality between two groups. The analysis was performed according to the intention-to-treat principle. No interim analysis was performed during the study period.

\section{RESULTS}

A total of 115 patients reported to the emergency with alleged consumption of ALP. 53 patients were fulfilled the inclusion criterion over a period of 12 months, but data from only 50 were available for final analysis. Among the total study group, $70 \%$ were males (38\% in NAC group, $32 \%$ in placebo) and $30 \%$ were females. Majority of our patients were in the second to fourth decades of life with $64 \%$ of them under 30 years of age. In our study placebo group had younger patients ( $P$ value $<0.048)$. $54 \%$ of the study population reached the hospital within $3 \mathrm{~h}$ of ingestion and there was no delay in institution of therapy in the two groups [Table 1]. Both the groups received the same level of care with gastric decontamination using normal saline being performed in both. None of the patients received treatment with vegetable/coconut oil. Since all the patients had severe poisoning with shock, all of them received inotropic support. The overall level of supportive treatment was the same with all patients needing multiple inotropes during the course of illness.

Shortness of breath (86\%), oliguria (80\%), vomiting (78\%), and altered sensorium (24\%) were the primary symptoms. The frequency of occurrence of symptoms was equal in both the groups [Table 1].

Overall mortality in the study population was $88 \%$. In NAC group, the unfavorable outcome was seen in $87.5 \%$ whereas in the placebo group, it was seen in $88.5 \%$. There was no statistically significant difference in the outcome among the two groups [Table 1].

Most of the patients in the study group died within $12 \mathrm{~h}$ of admission (70.5\%). Only 10 patients (9.1\%) survived for more than $24 \mathrm{~h}$. Out of these 10, 6 patients ultimately survived and were discharged.

The baseline HR and central venous pressure (CVP) were significantly elevated in the nonsurvivors in both the groups. The HR and SBP responded to treatment in survivors and the mean duration of improvement in these parameters was $9 \pm 2.1 \mathrm{~h}$. The mean $\mathrm{pH}$ and $\mathrm{HCO}_{3}$ levels were significantly different in survivors as compared to nonsurvivors at presentation [Table 2]. Mean $\mathrm{pH}$ and $\mathrm{HCO}_{3}$ levels improved in survivors but the time taken for improvement in these parameters was $11 \pm 1.4 \mathrm{~h}$.

In the NAC group, mean total leukocyte count (TLC) was 20,500 and mean platelet count was 257,000 in the nonsurvivors whereas in the survivors, mean TLC was 11,400 and mean platelet count was 262,000 , this difference was statistically significant $(P=0.005)$. In the placebo group, both the TLC and platelet count were comparable in survivors and nonsurvivors.

Baseline renal dysfunction, evidenced by raised serum creatinine and transaminitis, evidence by 3 -fold rise in liver enzymes, in both the groups was associated with adverse outcome. These levels returned to normal in survival by the 
time of discharge. There was however no difference in serum potassium and magnesium levels, amongst survivors or nonsurvivors, in both the study groups [Table 2].

Among the study population, 68\% had ECG abnormalities whereas $32 \%$ had normal sinus rhythm. The presence of an abnormal ECG was significantly associated with adverse outcome in both the groups $(P \leq 0.001)$.

The Mean dose NAC administered in survivors was $19 \mathrm{~g}$ and in nonsurvivors was $12.15 \mathrm{~g}$. This difference was statistical

\begin{tabular}{|c|c|c|c|}
\hline Characteristic & $\begin{array}{c}\text { NAC }(n=24) \\
(\%)\end{array}$ & $\begin{array}{c}\text { Placebo }(n=26) \\
(\%)\end{array}$ & $P$ \\
\hline \multicolumn{4}{|l|}{ Gender } \\
\hline Male & $19(38)$ & $16(32)$ & 0.174 \\
\hline Female & $5(10)$ & $10(20)$ & \\
\hline \multicolumn{4}{|l|}{ Age group (years) } \\
\hline$<30$ & $12(24)$ & $20(40)$ & 0.048 \\
\hline$>30$ & $12(24)$ & $6(12)$ & \\
\hline \multicolumn{4}{|l|}{ Arrival time (h) } \\
\hline$<3$ & $9(18)$ & $18(36)$ & 0.025 \\
\hline$>3$ & $15(30)$ & $8(16)$ & \\
\hline \multicolumn{4}{|l|}{ First aid } \\
\hline Received & $11(22)$ & $10(20)$ & 0.598 \\
\hline Not received & $13(26)$ & $16(32)$ & \\
\hline \multicolumn{4}{|l|}{ Symptoms } \\
\hline Vomiting & $19(38)$ & $20(40)$ & 0.848 \\
\hline $\begin{array}{l}\text { Shortness of } \\
\text { breath }\end{array}$ & $20(40)$ & $23(46)$ & 0.602 \\
\hline $\begin{array}{l}\text { Altered } \\
\text { sensorium }\end{array}$ & $5(10)$ & $7(14)$ & 0.614 \\
\hline Oliguria & $18(36)$ & $22(44)$ & 0.396 \\
\hline Inotropes & $24(48)$ & $26(52)$ & \\
\hline
\end{tabular}

NAC: N-acetyl cysteine significant. This disparity could be due to early mortality $(<6 \mathrm{~h})$ which devoid the nonsurvivors of getting a full dose of NAC. No significant side effects were encountered in the patients receiving NAC.

Hemodynamic parameters in nonsurvivors were similar in both the groups at $6 \mathrm{~h}, 12 \mathrm{~h}$, and $24 \mathrm{~h}$ interval. Survivors in both the groups responded equally to standard treatment with inotropes and sodium bicarbonate therapy. Out of the 10 survivors at $24 \mathrm{~h}$, requirement for inotropes did come down only in 6 ultimate survivors.

The total duration of stay in the hospitals in survivors in both groups was also comparable. Only 1 patient in each group developing hospital-acquired pneumonia. Out of the 6 survivors, 3 in each group, none developed evidence of capillary leak syndrome. There was no delayed complication in survivors at 2 weeks follow-up.

When we plotted the Kaplan-Meier curve, we observed that there was no statistically significant difference amongst both the groups as far as survival was concerned [Figure 1]. As far as the need for inotropes and duration of survival were considered, NAC administration did not result in significant difference when compared with placebo [Table 3].

\section{Discussion}

This was an intervention study to evaluate the effects of NAC on mortality and morbidity in patients with severe ALP poisoning characterized by shock at the time of presentation. Our study population consisted of 50 patients of which majority were in the second to fourth decades of life with $64 \%$ of them younger than 30 years of age. This is similar to our earlier observations that majority of our victims presenting with poisoning are in the age range of 21-30 years (mean age $=27.8$ years) ${ }^{\left[{ }^{[1]}\right.}$ Similarly findings (mean age of 32 years)

Table 2: Biochemical and hematological parameter in the study group

\begin{tabular}{|c|c|c|c|c|c|c|c|c|c|c|}
\hline \multicolumn{6}{|c|}{ NAC } & \multicolumn{5}{|c|}{ Placebo } \\
\hline \multicolumn{3}{|c|}{ Died $(n=18)$} & \multicolumn{3}{|c|}{ Survived $(n=3)$} & \multicolumn{2}{|c|}{ Died $(n=18)$} & \multicolumn{3}{|c|}{ Survived $(n=3)$} \\
\hline Parameter & Mean & SD & Mean & SD & $P$ & Mean & SD & Mean & SD & $P$ \\
\hline SBP & 76.22 & 8.45 & 85.33 & 5.03 & 0.089 & 72.29 & 8.42 & 85.33 & 5.03 & 0.017 \\
\hline HR & 137.24 & 12.17 & 114.67 & 10.26 & 0.006 & 141.57 & 14.34 & 116.0 & 17.32 & 0.009 \\
\hline CVP & 21.40 & 3.95 & 12.0 & 0.0 & 0.001 & 23.36 & 3.28 & 14.0 & 3.46 & $<0.001$ \\
\hline $\mathrm{pH}$ & 7.10 & 0.16 & 7.34 & 0.02 & 0.090 & 7.12 & 0.11 & 7.35 & 0.03 & 0.07 \\
\hline $\mathrm{HCO}_{3}^{-}$ & 11.14 & 3.58 & 16.67 & 1.15 & 0.054 & 10.8 & 4.02 & 17.27 & 7.34 & 0.11 \\
\hline TLC & 20,500 & 4648 & 11,400 & 5391 & 0.005 & 18,200 & 5672 & 11,300 & 5672 & 0.06 \\
\hline Platelet & 257,000 & 82,470 & 262,000 & 73,020 & 0.92 & 224,000 & 85,663 & 261,000 & 30,088 & 0.47 \\
\hline AST & 195 & 116 & 47.33 & 1.15 & 0.021 & 159.50 & 63.14 & 56.67 & 27.15 & 0.013 \\
\hline ALT & 232.67 & 125.29 & 88 & 9.16 & 0.032 & 189.72 & 66.43 & 64.33 & 32.47 & 0.005 \\
\hline Bilirubin & 1.18 & 0.52 & 0.67 & 0.11 & 0.127 & 1.21 & 0.68 & 0.70 & 0.17 & 0.219 \\
\hline Potassium & 4.75 & 0.99 & 3.6 & 0.22 & 0.063 & 4.53 & 1.02 & 4.46 & 0.23 & 0.91 \\
\hline Creatinine & 3.18 & 1.73 & 0.53 & 0.11 & 0.016 & 3.27 & 1.71 & 0.64 & 0.32 & 0.018 \\
\hline Magnesium & 2.29 & 0.65 & 2.28 & 0.27 & 0.986 & 1.21 & 0.70 & 0.10 & 0.17 & 0.871 \\
\hline
\end{tabular}

NAC: N-acetyl cysteine; SD: Standard deviation; SBP: Systolic blood pressure; HR: Heart rate; CVP: Central venous pressure; TLC: Total leukocyte count; AST: Aspartate transaminase; ALT: Alanine transaminase 


\begin{tabular}{lcccc}
\hline \multicolumn{4}{l}{ Table 3: Duration of stay of the mortality group $(\boldsymbol{n = 4 4 )}$} \\
\hline Duration & $\begin{array}{c}\text { NAC } \\
(\boldsymbol{n = 2 1 )}(\boldsymbol{( \% )})\end{array}$ & $\begin{array}{c}\text { Placebo } \\
(\boldsymbol{n}=\mathbf{2 3})(\boldsymbol{\%})\end{array}$ & Total (\%) & $\boldsymbol{P}$ \\
& $8(18.2)$ & $7(15.9)$ & $15(34.1)$ & \\
\hline$<6$ & $8(18.2)$ & $8(18.2)$ & $16(36.4)$ & 0.807 \\
$6-12$ & $3(6.8)$ & $6(13.6)$ & $9(20.5)$ & \\
$12-24$ & $2(4.5)$ & $2(4.5)$ & $4(9.1)$ & \\
$>24$ & \multicolumn{4}{l}{}
\end{tabular}

have been reported from Iran as well. ${ }^{[3]}$ This indicates that ALP is an agent used commonly by the younger generation for self-harm purpose.

In our study, we observed male preponderance. This is consistent with our own previous experience and the experience world over with males being affected 2-4-folds more with ALP. ${ }^{[1,9-11]}$ Although the exact cause of this association is not known but easier access to the fumigant due to their nature of work may be responsible.

Shortness of breath, oliguria, and vomiting were the dominant symptoms with alteration in mentation being observed in only $25 \%$ patients. These results are consistent with earlier observations of many researchers that vomiting, abdominal pain, and anuria are the most common symptoms. . $^{[2,3,7,12-14]}$ Vomiting and abdominal pain could be due to local effects of ALP over gastric mucosa and shortness of breath is secondary to myocarditis. ${ }^{[2,12,14]}$

Majority (54\%) of the patients arrived at our hospital within $3 \mathrm{~h}$ of ingestion which is significantly earlier than the $5.3 \mathrm{~h}$ observed by Louriz et al. and $4.2 \mathrm{~h}$ observed by Shadnia et $a l .^{[13,15]}$ Early reporting following ingestion could indicate either an increased awareness regarding the potential lethality of this poison or an early referral to a tertiary care center from periphery. Interestingly, it was found that the mortality was very high especially among those who arrived within $6 \mathrm{~h}$ of ingestion. It indicates the rapidity of action of this poison, early establishment of tissue hypoxia which might be responsible for mortality even after early institution of supportive therapy. ${ }^{[2]}$

As in earlier studies, in our study too, lower SBP, higher $\mathrm{HR}$, and higher CVP $(>18)$ at presentation were found to be associated with poor outcome. ${ }^{[9]}$ This indicates severe myocardial depression at presentation to be an indicator of poor prognosis in patients with ALP poisoning. Since the commonly used severity scoring systems (APACHE, SAPS, and SOFA) are not specific to any poisoning, we did not use any of these scoring systems to assess severity. All patients in our study group were comparable in severity as "severe poisoning" due to the presence of circulatory shock.

Among biochemical markers, only serum creatinine $>2 \mathrm{mg} \%$ at the time of presentation was associated with increased mortality in both the groups. This result is consistent with the study by Louriz et al., where it was shown that serum creatinine influenced the mortality. ${ }^{[13]}$ There is no evidence to implicate ALP as a direct nephrotoxic agent. Acute kidney

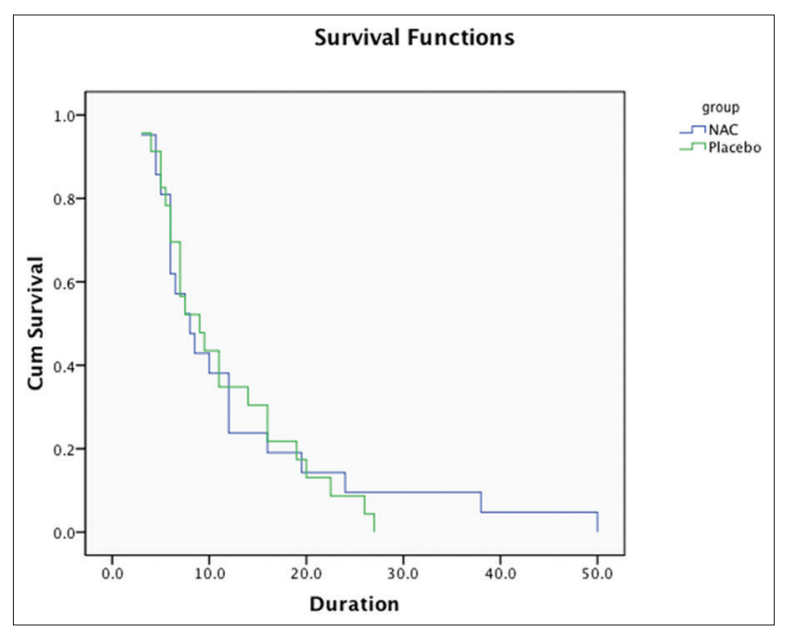

Figure 1: Kaplan-Meier curve for comparison of survival in both the groups

injury in this setting is likely to be secondary to severe myocardial depression resulting in persistent hypoperfusion reflecting as the elevated serum level of creatinine.

Mortality of $88 \%$ in our study population is higher, but the overall mortality reported in ALP poisoning ranges from $37 \%$ to $100 \%{ }^{[7,13,15-19]}$ This difference could be due to the study design. Our study included patients with established shock, whereas some studies include both normotensive and hypotensive patients in the study population. High mortality rate $(>60 \%)$ has been reported from some highly equipped centers. ${ }^{[18,19]}$ The higher mortality rates at tertiary care centers could be due to a referral bias as more severe patients are referred to these centers and mild cases managed at periphery units or this could be an underestimation as many severely ill patients would die even before they reach tertiary care center.

In one Indian study, where NAC was used in an experimental setup, NAC administration, before exposure to ALP, increased the survival time $(P<0.005)$, and stabilized the HR and BP in rats. ${ }^{[20]}$ It was also shown that NAC pretreatment, in addition to posttreatment decreased the oxidative stress on the tissues and thereby increasing the survival. ${ }^{[20]}$ Similar findings have been reported by Tehrani et al. in a prospective study. In this study, NAC administration in high dose $(140 \mathrm{mg} / \mathrm{kg} /$ intravenous (iv) infusion as a loading dose and $70 \mathrm{mg} / \mathrm{kg} / \mathrm{iv}$ infusion every $4 \mathrm{~h}$ up to 17 doses) resulted in amelioration of the oxidative stress, resulting in significant survival benefit. ${ }^{[7]}$ These results are in contrast to our findings. The reason could be the fact that NAC was used in a lower dose. There may be a role of NAC in reducing the oxidative stress, but we did not study it. NAC administration in the same dose used to treat paracetamol overdose did not translate into survival/mortality benefit in our study group.

In our study population, there is a statistically significant difference in NAC dose received by survivors and nonsurvivors. Since majority of the severally ill patients died within first $3 \mathrm{~h}$, they may not have received the complete dose of NAC. This 
indicates that the dosing regimen used in our study may not be ideal for severe ALP patients. We would need to carry the study using a different regimen, where the maximum dose of NAC is administered within first 3-6 h.

Since there is no established clinical scoring system to categorize the severity of the poisoning, it may be difficult to compare two studies as the severity of illness may have been different. Maybe our study population had severe toxicity at presentation and hence no survival benefit was noted with NAC. Larger multi-centric studies are needed to establish the role of NAC in ALP poisoning.

\section{Strengths and limitations}

This was a prospective study at a single center; therefore almost all the patients received similar kind, supportive therapy in the same setup. Small number of patients, early mortality, and inability to provide a maximum dose of NAC in first $3 \mathrm{~h}$ could be the important limitations of our study.

\section{Conclusions}

NAC is a powerful antioxidant and has shown a survival benefit in animal models when used as a pretreatment in ALP poisoning. In established cases of severe ALP poisoning, associated with shock at presentation, its administration did not confer any survival benefit. Further studies with the different dosing regimen, in patients with less severe form of poisoning, are warranted.

\section{Financial support and sponsorship}

Nil.

\section{Conflicts of interest}

There are no conflicts of interest.

\section{RefEREnCES}

1. Murali R, Bhalla A, Singh D, Singh S. Acute pesticide poisoning: 15 years experience of a large North-West Indian hospital. Clin Toxicol (Phila) 2009; 47:35-8.

2. Singh S, Bhalla A, Verma SK, Kaur A, Gill K. Cytochrome-c oxidase inhibition in 26 aluminum phosphide poisoned patients. Clin Toxicol (Phila) 2006;44:155-8.

3. Moghadamnia AA, Abdollahi M. An epidemiological study of poisoning in northern Islamic Republic of Iran. East Mediterr Health J 2002;8:88-94.

4. Abder-Rahman HA, Battah AH, Ibraheem YM, Shomaf MS,
el-Batainch N. Aluminum phosphide fatalities, new local experience. Med Sci Law 2000;40:164-8.

5. Akkaoui M, Achour S, Abidi K, Himdi B, Madani A, Zeggwagh AA, et al. Reversible myocardial injury associated with aluminum phosphide poisoning. Clin Toxicol (Phila) 2007;45:728-31.

6. Anand R, Kumari P, Kaushal A, Bal A, Wani WY, Sunkaria A, et al. Effect of acute aluminum phosphide exposure on rats: A biochemical and histological correlation. Toxicol Lett 2012;215:62-9.

7. Tehrani H, Halvaie Z, Shadnia S, Soltaninejad K, Abdollahi M. Protective effects of $\mathrm{N}$-acetylcysteine on aluminum phosphide-induced oxidative stress in acute human poisoning. Clin Toxicol (Phila) 2013;51:23-8.

8. Anand R, Sharma DR, Verma D, Bhalla A, Gill KD, Singh S Mitochondrial electron transport chain complexes, catalase and markers of oxidative stress in platelets of patients with severe aluminum phosphide poisoning. Hum Exp Toxicol 2013;32:807-16.

9. Jaiswal S, Verma RK, Tewari N. Aluminum phosphide poisoning: Effect of correction of severe metabolic acidosis on patient outcome. Indian J Crit Care Med 2009;13:21-4.

10. Kapoor AK, Sinha US, Singh AK, Mehrotra R. An epidemiological study of aluminium phosphide poisoning in Allahabad. Indian J Forensic Med Toxicol 2006;4:1-7.

11. Chopra JS, Kalra OP, Malik VS, Sharma R, Chandna A. Aluminium phosphide poisoning: A prospective study of 16 cases in one year. Postgrad Med J 1986;62:1113-5.

12. Singh S, Singh D, Wig N, Jit I, Sharma BK. Aluminum phosphide ingestion - A clinico-pathologic study. J Toxicol Clin Toxicol 1996;34:703-6.

13. Louriz M, Dendane T, Abidi K, Madani N, Abouqal R, Zeggwagh AA. Prognostic factors of acute aluminum phosphide poisoning. Indian J Med Sci 2009;63:227-34.

14. Siwach SB, Singh H, Jagdish, Katyal VK, Bhardwaj G. Cardiac arrhythmias in aluminium phosphide poisoning studied by on continuous holter and cardioscopic monitoring. J Assoc Physicians India 1998;46:598-601.

15. Shadnia S, Mehrpour O, Abdollahi M. Unintentional poisoning by phosphine released from aluminum phosphide. Hum Exp Toxicol 2008;27:87-9.

16. Siwach SB, Yadav DR, Arora B, Dalal S, Jagdish. Acute aluminum phosphide poisoning - An epidemiological, clinical and histo-pathological study. J Assoc Physicians India 1988;36:594-6.

17. Chugh SN, Chugh K, Ram S, Malhotra KC. Electrocardiographic abnormalities in aluminium phosphide poisoning with special reference to its incidence, pathogenesis, mortality and histopathology. J Indian Med Assoc 1991;89:32-5.

18. Bajaj R, Wasir HS, Aggarwal R. Aluminium phospide poisoning clinical toxicity and outcome in eleven intensively monitored patients. Natl Med J India 1988;1:270-4.

19. Katira R, Elhence GP, Mehrotra ML, Srivastava SS, Mitra A, Agarwala R, et al. A study of aluminum phosphide (AlP) poisoning with special reference to electrocardiographic changes. J Assoc Physicians India 1990;38:471-3.

20. Azad A, Lall SB, Mittra S. Effect of N-acetylcysteine and L-NAME on aluminium phosphide induced cardiovascular toxicity in rats. Acta Pharmacol Sin 2001;22:298-304. 